\title{
The Challenges of Detecting Risk Factors for the Development of Atherosclerosis
}

\author{
Dinarević SM*, Topić B, Jurišić S, Prohić S, Sporišević L, Saric S, Sarić GK, Krželj V, Jogunčić A and Ramić A
}

Committee for Cardiovascular Pathology, Academy of Sciences and Arts, Sarajevo, Bosnia and Herzegovina

\begin{abstract}
The most frequent disease of the arteries is atherosclerosis which is characterized by lumen reduction of blood vessels due to local thickening of internal blood vessels caused by plaque/atheroma. As a cardiovascular disease, atherosclerosis is an interdisciplinary problem and one of the leading causes of death in developed countries. It begins in childhood, goes a long time without manifesting symptoms, increasing with age it begins to seriously threaten health. The most dangerous risk factors for the development of atherosclerotic disease are: Hyperlipidaemia, hypertension, smoking, diabetes, high fibrinogen, excessive weight and physical inactivity.
\end{abstract}

Keywords: Atherosclerosis; Hyperlipidaemia; Hypertension; Myocardial infarction; Parodontal disease

\section{Introduction}

The primary intention of prevention of atherosclerosis is to preclude the occurrence of risk factors for atherosclerosis, and the secondary is to prevent the development or aggravation of the illness along with the reduction or control of existing risks. Primary prevention should begin as early as possible, even in childhood, creating a healthy diet, eliminating smoking, regular physical activity, which will prevent or at least slow the development of atherosclerosis. The consequences of atherosclerosis are: coronary or ischemic heart disease, especially myocardial infarction, cerebrovascular disease and cerebrovascular accident ( $80 \%$ of all heart attacks and brain due to atherosclerosis), narrowing or blockage of peripheral arteries, carotid arteries. Since there is no specific cure for atherosclerosis, the best way to prevent this disease, is prevention.

Some authors pointed out the possible connection between parodontal disease in pregnant women with the risk of preterm delivery, new-borns of low gestational age with low birth masses and possible cardiovascular disease [1-7].

\section{Oral health}

Appropriate oral health reflects and influences general health and the quality of life. The oral cavity is an integral part of the human organism and therefore there exists a great connection between oral health and systemic health. Not only do some systemic diseases such as diabetes, osteoporosis, HIV infection, trisomy 21 have a predisposition for periodontitis but an opposite applies. Susceptibility to certain systemic disease is higher in patients with periodontitis than in healthy people: chronic periodontitis is a risk factor for future cardiovascular disease, pregnant women with chronic periodontitis have more frequent have preterm birth and new-borns have a low birth weight. The explanation for the pathophysiological mechanisms of paradont focus and systemic disease is associated with elevated levels of circulating pro-inflammatory cytokines and prostaglandins derived from: diseased parodont, gram negative bacteria and their endotoxinlike substances, that appear from subgingival biofilms immediately entering the bloodstream. The dominant problems of everyday dental practice are: caries, periodontal disease, occlusal abnormalities, the relationship of oral and general health and a holistic approach to the patient. Caries and periodontal disease are of an infectious aetiology therefore the prevention of dental caries and periodontal disease means preventing odontogenic focuses. A periodontal pocket is a risk factor for the development or worsening of systemic - focal disease, because the infection is always present in it; a pocket flora is various, massive, virulent and penetrates the soft wall of the pocket, the pocket is under constant mechanical stimulation during chewing, swallowing and speech, all of which favour the penetration of bacteria into circulation and the formation of transient bacteremia. Dental caries and periodontal disease are the most common and significant oral disease, they can cause and aggravate numerous other disease: of the cardiovascular system (infective endocarditis, atherosclerosis, myocarditis and myocardial infarction), of the respiratory system (pneumonia, chronic obstructive pulmonary disease, bronchial asthma and pulmonary abscess), neurological disorders (cerebral infarction and cerebral abscess), diabetes mellitus, rheumatoid arthritis, Alzheimer's disease, and other illnesses) [8]. Interdisciplinary cooperation in the elimination of potential negative effects of periodontal infections will result in better systemic health Atherosclerosis is the basis for all cardiovascular disease. Periodontal pathogens can directly infect the vascular endothelium and atherosclerotic plaque causing inflammation. Then, they are capable of producing a variety of virulence factors (adhesions, haemolysis), which have adverse effects on the vascular system resulting in platelet aggregation and adhesion; in addition, lipid clusters are formed with deposits of cholesterol that contribute to atheroma formation. The treatment of chronic periodontitis reduces systemic inflammation factors.

\section{Pregnancy}

Pregnancy is a state in which there are complex physical and physiological changes, which have important effects on multiple systems of organs. High levels of circulating oestrogen during pregnancy are associated with high incidence of gingivitis and gingival hyperplasia or certain forms of periodontal disease [9]. It is believed that approximately $40 \%$ of pregnant women have a certain form of periodontal disease [8-10]. Offenbacher et al. first suggested a possible link between periodontal disease and risks for child delivery of a low

*Corresponding author: Dinarević SM, Committee for Cardiovascular Pathology, Academy of Sciences and Arts, Sarajevo, Bosnia and Herzegovina, Tel: +387 33 560-700; E-mail: dsenka@bih.net.ba

Received October 01, 2018; Accepted October 25, 2018; Published October 28, 2018

Citation: Dinarević SM, Topić B, Jurišić S, Prohić S, Sporišević L, et al. (2018) The Challenges of Detecting Risk Factors for the Development of Atherosclerosis. J Cardiovasc Dis Diagn 6: 342. doi: 10.4172/2329-9517.1000342

Copyright: (C) 2018 Dinarević SM, et al. This is an open-access article distributed under the terms of the Creative Commons Attribution License, which permits unrestricted use, distribution, and reproduction in any medium, provided the original author and source are credited. 
gestational age or small birth weight [11]. Many researchers suggest a possible link between periodontal disease in pregnant women with a risk for preterm delivery, respectively, the birth of babies with low birth weight. Researches show that in pregnant women with periodontal disease there is a 2-7 times higher risk for prematurity. Morre et al. found a large number of foetal deaths among mothers with periodontal disease [12]. However, a focal infection may affect prematurity (birth before 37 weeks gestation) of neonates and neonatal reduction in weight (weight $<2500 \mathrm{gm}$ ). Bacteraemia of periodontal pathogens trasplacentary can lead to intrauterine infection. Proinflammatory cytokines release the (LPS) endotoxin that precipitates in premature labour. LPS - bacterial lipopolysaccharides, are the major molecular component of the outer membrane of Gram-negative bacteria and serve as a physical barrier providing the bacteria protection from its surroundings. That is why dentists need to motivate, educate and instruct pregnant women towards a higher level of oral hygiene and to repair all dento-oral lesions in dental therapeutic procedures, especially periodontal pockets, thereby reducing the number of premature births. It is believed that the Gram-negative anaerobic bacteria, present in the periodontal tissue, can be a source for endotoxin and lipopolysaccharides, that lead to high levels of inflammatory mediators - interleukin- 6 (IL-6), interleukin 8 (IL-8), Interleukin - 1 beta (IL$1 \beta)$, and prostaglandin E2 (PGE2) and tumor necrosis factor-alpha (TNF- $\alpha$ ), which are transferred to the uterus, cervix and placenta causing premature birth or the birth of children of a small birth weight. Jeffcoat et al. whilst investigating the connection between periodontal disease of pregnant women and preterm birth in group of 1313 pregnant women, found that a moderate to severe form of periodontal disease, diagnosed in early pregnancy, was associated with an increased risk for premature delivery, independently of other traditional risk factors for prematurity [13]. During pregnancy, there is an increased susceptibility to caries due to: the increased acidity of the oral cavity, the increased consumption of refined sugars and poor oral hygiene [14]. Caries bacteria in children are usually transmitted by direct transmission through the mother's saliva. Mothers with high titres of Streptococcus mutants in their saliva are going to substantially transmit the bacteria to their baby - by vertical transmission, creating conditions for early childhood caries. Of course, the time and frequency of the transmission of bacteria, the child's preference for the accumulation of bacteria on its teeth, the composition and flow of the child's saliva, the amount of refined sugar in the baby's food, are all significant predictors of early children's caries [15]. The incidence of births of premature infants and new-borns of a small birth weight is between $5-18 \%$, depending on the geographical area and population characteristics. Due to the immaturity of their organ systems, premature babies and infants of a small birth weight are among in vulnerable group of infants - complications due to prematurity are the leading cause of death in children under five years of age [16]. It is very important to determine risk factors that can lead to the risk of the prematurity of new-borns and new-borns of a small birth weight, i.e. with knowledge of the risk factors, it is possible to substantially eliminate or reduce the risk of premature baby birth or the birth of children with a small weight and to decrease the rate of perinatal mortality and possible complications. Preterm children or infants of a small birth weight exhibit a higher incidence of cardiovascular risk factors (obesity, hypertension, dyslipidaemia), and type 2 diabetes mellitus [16]. Animal and epidemiological studies indicate that conditions of elevated levels of glucocorticoids intrauterine during life, programme the hypothalamus-pituitaryadrenal gland axis that plays a key role in the higher incidence of cardiovascular risk in premature infants and children of a small birth weight [17]. Apart from the role of microbiome mouth (microbiome
- all microbes, their genome and mutual interaction in a particular environment) as a risk factor for premature delivery or the birth of new-born of small birth weight, it is possible that the microorganisms of the oral cavity condition chronic inflammation that can represent an atherosclerotic cardiovascular risk factor. Adequate prenatal care should include oral health care of pregnant women, i.e. for pregnant women, there is a need to point out the importance of practicing regular oral hygiene and the need for periodic or as many as or as frequently as needed dental check-ups. The sufficient screening/screening of oral health status of pregnant women is not carried out in daily work, so with screening status of oral health in a greater number of pregnant women, including the assessment of oral hygiene, we would be able to timely identify pregnant women who have dental caries respectively periodontal disease [18]. With timely dental treatment we could reduce the incidence of dental caries and periodontal disease in pregnant women and may reduce the incidence of preterm delivery and the birth of new-borns of a small birth weight, an early childhood caries and predictors of early atherosclerotic cardiovascular risk (increased body mass index, blood pressure and thickening of the carotid intima-media complex). In a cohort of children, who are preterm or have a low birth weight, a certain number of children age 3 have a greater body mass index, a higher value of systolic and diastolic blood pressure, as well as a thickening of the intima-media complex of the carotid artery with incipient signs of cardiovascular system disease [19].

Insufficient insight into the possible pathological implications of the oral health status of pregnant women to premature expression of cardiovascular risk factors in children, initiated this research.

The impact of oral health of pregnant women on the cardiovascular health of children is a Project within the South-eastern European region that runs by the Committee of the Cardiovascular Disease Department of Medical Sciences of Academy of Arts and Sciences of Bosnia and Herzegovina. During 2017, the first phase of research was completed according to plan/lasted for 12 months. In this study 43 pregnant women from Bosnia and Herzegovina and Croatia were included.

\section{The Project's Common Goals are to Give Answers to}

Does and in what capacity the oral health of pregnant women influence pregnancy? Does insufficient oral health of pregnant women (periodontal disease and certain forms of caries) influence gestational age, birth mass of children or oral and cardiovascular health of newborn's, infants and small children? Is chronic inflammation of the oral cavity (periodontal disease and caries) in pregnant women a atherosclerotic and cardiovascular risk factor, that is; do preschool children whose mothers during pregnancy had periodontal disease and/or caries, have a more prominent predictor of early cardiovascular risk (increased body mass index, high value of blood pressure and thickening of intima-media carotids complex) in comparison to children whose mothers during pregnancy had good oral health?

To achieve these goals, we are conducting the research that can last up to 48 months, using a multidisciplinary approach which includes: A gynaecologist, a dentist, a paediatrician, a radiologist, a cardiologist, nutritionists, epidemiologists and statistics. These examinations integrated research from 3 respected centres in Bosnia and Herzegovina and Croatia using combined experience and skills. The aim of this research is to investigate more prominent predictors of early cardiovascular risk increased body mass index, high values of blood pressure and the thickening of the intima-media carotids complex in comparison to children whose mothers had good oral health during pregnancy. 
Citation: Dinarević SM, Topić B, Jurišić S, Prohić S, Sporišević L, et al. (2018) The Challenges of Detecting Risk Factors for the Development of Atherosclerosis. J Cardiovasc Dis Diagn 6: 342. doi: 10.4172/2329-9517.1000342

Page 3 of 9

We are presenting the data on the I phase of this Project conducted in: Sarajevo, Mostar, and Split. The plan is to the finish project in 2019 the II phase, and in 2020 the III phase.

\section{The Survey is Designed as a Cohort Study}

It included mothers/pregnant women selected by random selection (randomized sampling). During regular gynaecological and obstetricexamination (being I trimester, if necessary, II and III trimester of gestation) a suggestion was given to pregnant women to do their dental examination in order to assess their oral health status. The general health status of the pregnant women was determined on the basis of an assessment of their medical records. The research did not include: Pregnant women with cardiovascular diseases, diabetes mellitus, kidney disease or any chronic illnesses. The survey testing assesses the habits of pregnant women: eating habits, physical activity, alcohol consumption, drugs and smoking.

II phase: The children would be evaluated as new-borns, preterm infants, new-borns of a desirable body weight and new-born of a small birth weight, they would be followed up to their third or fourth year of life. During the systematic review (the first month of life, the first year, the third and fourth year of life) paediatricians should evaluate: the basic characteristics related to pregnancy and childbirth, analysis of the eating habits of children, anthropometric parameters, determine blood pressure values and while radiologists determine the value of complex

\begin{tabular}{|c|c|}
\hline $\mathbf{N}$ & 43 \\
\hline Age (mean) & $30.7 \pm 5.7$ \\
\hline \multicolumn{2}{|c|}{ Pregnancy status } \\
\hline Normal & $39(90.70 \%)$ \\
\hline With complications & $4(9.30 \%)$ \\
\hline \multicolumn{2}{|c|}{ Education status } \\
\hline High school & $8(18.60 \%)$ \\
\hline Senior high school & $4(9.30 \%)$ \\
\hline University education & $31(72.10 \%)$ \\
\hline \multicolumn{2}{|c|}{ Diseases during pregnancy } \\
\hline Without & $37(86.05 \%)$ \\
\hline Rare/Lighter illnesses & $4(9.3 \%)$ \\
\hline With bigger complications & $2(4.65 \%)$ \\
\hline \multicolumn{2}{|c|}{ How often do you brush your teeth? } \\
\hline At least $2 \times$ per day & $27(62.8 \%)$ \\
\hline After each meal & $16(37.2 \%)$ \\
\hline \multicolumn{2}{|c|}{ How long it takes to brush your teeth? } \\
\hline Between 1 and 3 min & $28(65.12 \%)$ \\
\hline Longer than $3 \mathrm{~min}$ & $14(32.56 \%)$ \\
\hline At most one minute & $1(2.32 \%)$ \\
\hline \multicolumn{2}{|c|}{ When do you brush your teeth? } \\
\hline After each meal & $7(16.3 \%)$ \\
\hline In the morning & $1(2.3 \%)$ \\
\hline In the evening & $3(6.98 \%)$ \\
\hline In the morning and in the evening & $32(74.42 \%)$ \\
\hline \multicolumn{2}{|c|}{ The most common reason for dental visit } \\
\hline Tooth repair & $35 \%$ \\
\hline Regular control & $53 \%$ \\
\hline Dental pain & $12 \%$ \\
\hline \multicolumn{2}{|c|}{ How many times did you visit a dentist last year? } \\
\hline $1 \times$ & $23 \%$ \\
\hline $2 \times$ & $46 \%$ \\
\hline Not remembering & $12 \%$ \\
\hline Didn't visit a dentist & $19 \%$ \\
\hline
\end{tabular}

Table 1: Dental status. intima-media carotid artery a cardiologist by echocardiography would evaluate the hemodynamic status of the respondents. The study would include children of proper health conditions, i.e. children with congenital anomalies or certain chronic illnesses would be excluded from the study. Dentists would judge the status of dental health of pregnant women and children and evaluate the appropriateness of the oral health of pregnant women and children. The research is based on the principles of the Helsinki Declaration from 1975 and its amendments in 2008. In order to implement the principles of ethical and bioethical research consent/approval of the appropriate ethics committees/commissions is required. Voluntary inclusion of pregnant women and children is confirmed by signing an informed consent form.

\section{Materials and Methods}

After signing the informed consent form i.e. informing mothers/ pregnant women, by research methodology the following tests are conducted I phase: - survey testing - dental examination. Evaluation of general health conditions and life habits of pregnant women, determining the basic core characteristics of oral health protection during pregnancy.

\begin{tabular}{|c|c|}
\hline \multicolumn{2}{|l|}{ Fruit } \\
\hline$>2$ per day & $65 \%$ \\
\hline $1 \times$ per day & $30 \%$ \\
\hline Several times per week & $5 \%$ \\
\hline \multicolumn{2}{|c|}{ Milk and milk products } \\
\hline$>2$ per day & $33 \%$ \\
\hline $1 \times$ per day & $49 \%$ \\
\hline $1 \times$ per week & $0 \%$ \\
\hline Several times per week & $9 \%$ \\
\hline Rarely or never & $9 \%$ \\
\hline \multicolumn{2}{|l|}{ Vegetables } \\
\hline $1 \times$ per day & $58 \%$ \\
\hline$>2$ per day & $23 \%$ \\
\hline $1 \times$ per week & $5 \%$ \\
\hline Several times per week & $14 \%$ \\
\hline \multicolumn{2}{|l|}{ Juices } \\
\hline $2+$ per day & $25 \%$ \\
\hline $1 \times$ per day & $26 \%$ \\
\hline $1 \times$ per week & $14 \%$ \\
\hline Several times per week & $7 \%$ \\
\hline Rarely or never & $28 \%$ \\
\hline \multicolumn{2}{|l|}{ Sweets } \\
\hline $1 \times$ per day & $28 \%$ \\
\hline $1 \times$ per week & $5 \%$ \\
\hline $2+$ per day & $23 \%$ \\
\hline Several times per week & $28 \%$ \\
\hline Rarely or never & $16 \%$ \\
\hline \multicolumn{2}{|l|}{ Meat } \\
\hline $2+$ per day & $25 \%$ \\
\hline $1 \times$ per day & $26 \%$ \\
\hline $1 \times$ per week & $14 \%$ \\
\hline Several times per week & $14 \%$ \\
\hline Rarely or never & $21 \%$ \\
\hline \multicolumn{2}{|l|}{ Fish } \\
\hline $2+$ per day & $5 \%$ \\
\hline $1 \times$ per day & $9 \%$ \\
\hline $1 \times$ per week & $46 \%$ \\
\hline Several times per week & $14 \%$ \\
\hline Rarely or never & $26 \%$ \\
\hline
\end{tabular}

Table 2: Eating habits. 
Citation: Dinarević SM, Topić B, Jurišić S, Prohić S, Sporišević L, et al. (2018) The Challenges of Detecting Risk Factors for the Development of Atherosclerosis. J Cardiovasc Dis Diagn 6: 342. doi: 10.4172/2329-9517.1000342

Page 4 of 9

\begin{tabular}{|c|c|c|c|c|c|c|}
\hline \multirow{2}{*}{ KEP index } & \multicolumn{2}{|c|}{$12.32 \pm 5.729$} & \multicolumn{2}{|c|}{ Plaque index } & \multicolumn{2}{|c|}{$0.3125 \pm 0.405$} \\
\hline & S1 & S2 & S3 & S4 & S5 & S6 \\
\hline A healthy periodental & $42.90 \%$ & $82.10 \%$ & $39.30 \%$ & $53.60 \%$ & $71.40 \%$ & $35.70 \%$ \\
\hline Bleeding & $42.90 \%$ & $14.30 \%$ & $46.40 \%$ & $35.40 \%$ & $25 \%$ & $53.60 \%$ \\
\hline Calculus & $7.10 \%$ & $3.60 \%$ & $7.15 \%$ & $7.20 \%$ & $3.60 \%$ & $10.70 \%$ \\
\hline Periodontal pocket $(4-5 \mathrm{~mm})$ & $7.10 \%$ & & $7.15 \%$ & $3.80 \%$ & -- & -- \\
\hline
\end{tabular}

Table 3: KEP index.

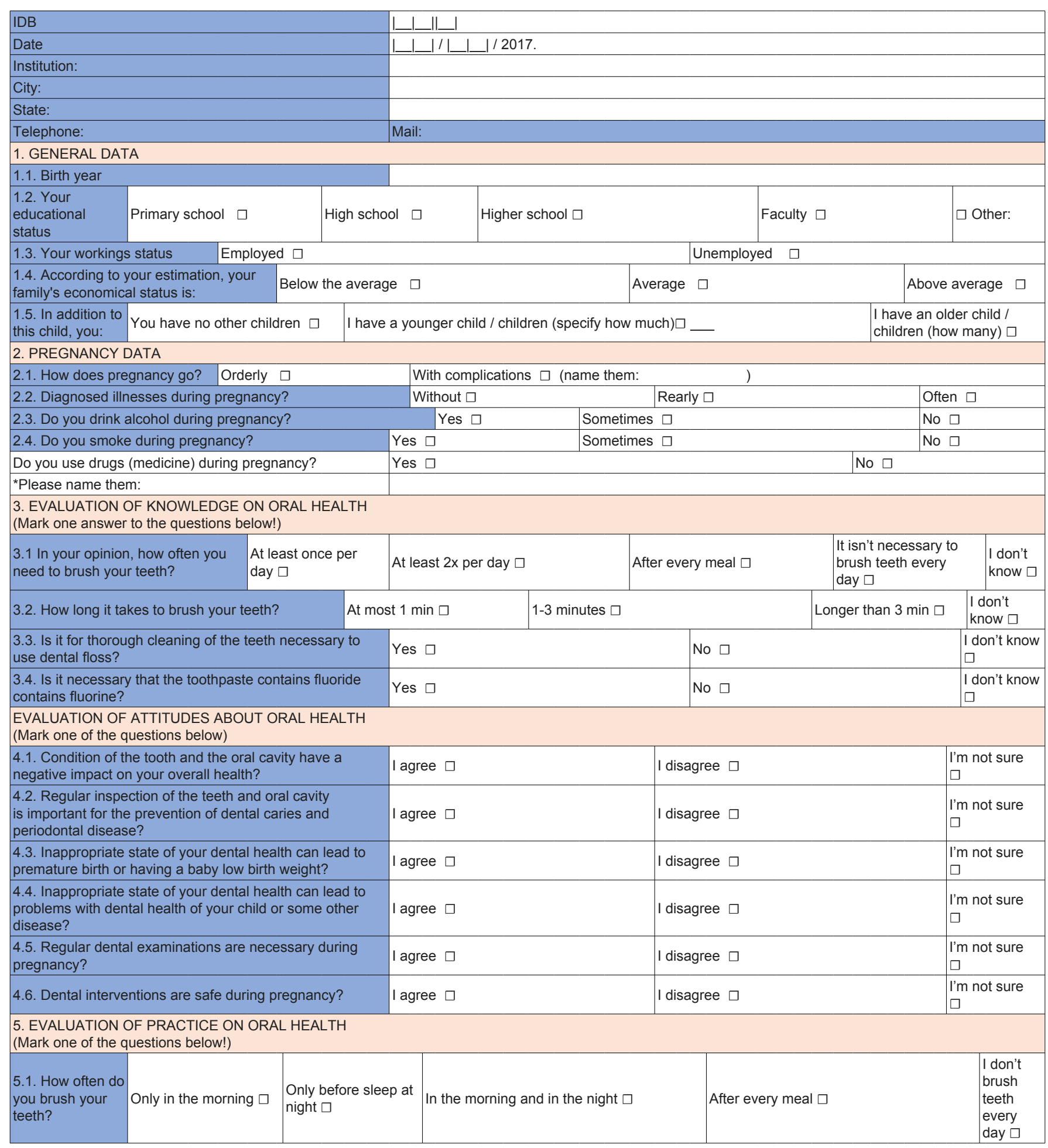


Citation: Dinarević SM, Topić B, Jurišić S, Prohić S, Sporišević L, et al. (2018) The Challenges of Detecting Risk Factors for the Development of Atherosclerosis. J Cardiovasc Dis Diagn 6: 342. doi: 10.4172/2329-9517.1000342

Page 5 of 9

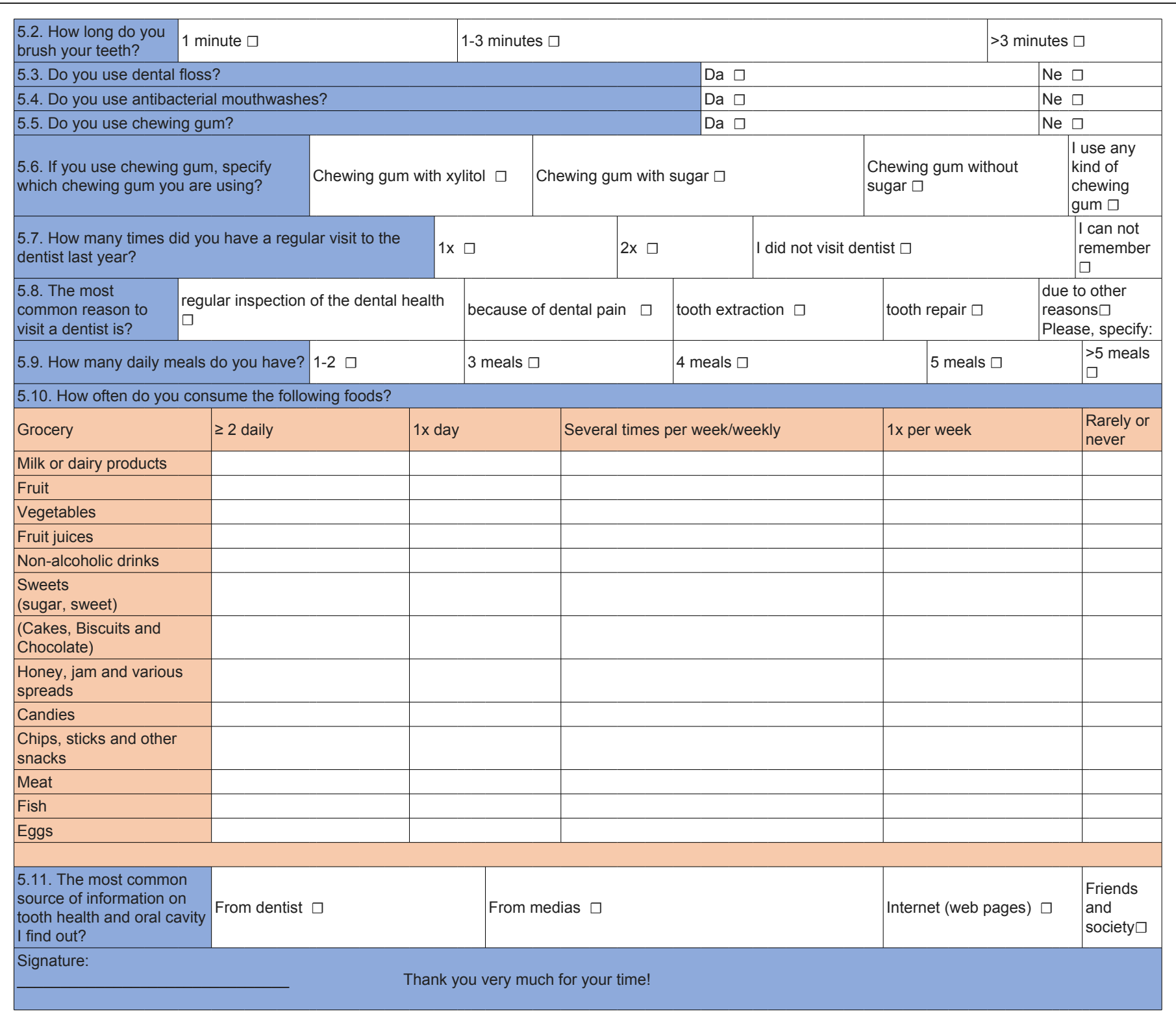

Figure 1: Questionnaire for mother: The impact of oral health of pregnant women on the cardiovascular health of children.

\section{Techniques of research}

Originally created questionnaires for mothers/pregnant women and children (general data, data from personal history, data on eating habits, data on harmful habits, data on physical activities and data on oral health); determination of initial caries, periodontal examination with complete examination of the oral cavity in mothers and children according to WHO recommendations; determination of body mass and height, calculation of body mass index; determination of blood pressure values in children; determination of carotid complex of intima-media artery by 2D Colour Doppler ultrasonography; 2D Colour Doppler echocardiography evaluation of the cardiovascular system; data base creation in MS Access or MS Office; evaluation of variables by statistical programs in consultation with statisticians; design and development of a web based data collection system for research data entry and analysis.

Survey sheets were originally designed, they include questions about their habits in food intake (frequency, quantity and types) and fluids with a Questioner of dental status in mothers (Figures 1-3).

\section{Anonymous questionnaire for gynecologists and dentists}

As a dentist, I avoid the application of local anaesthesia with adrenalin to pregnant women during all months of pregnancy? I avoid any kind of X-raying pregnant women? In pregnancy the extraction of a tooth under pain is not recommended? I avoid therapy of gravidity gingivitis in pregnant women in all phases of pregnancy? Trepanation of teeth, the cause of acute dentogen infection, and incisions are not recommended in pregnant women? The Study Workflow: Pregnant women-gynaecologist-dentist- radiologist- cardiologistepidemiologist.

\section{Research Data}

Preliminary study data I phase (2017-18): Mean age of 43 pregnant women is $30.7 \pm 5.7$ years; $90.7 \%$ pregnancy ran properly; complication detected in $9.3 \%$.

During pregnancy: $86.05 \%$ mothers had no new disease diagnosed. 
Citation: Dinarević SM, Topić B, Jurišić S, Prohić S, Sporišević L, et al. (2018) The Challenges of Detecting Risk Factors for the Development of Atherosclerosis. J Cardiovasc Dis Diagn 6: 342. doi: 10.4172/2329-9517.1000342

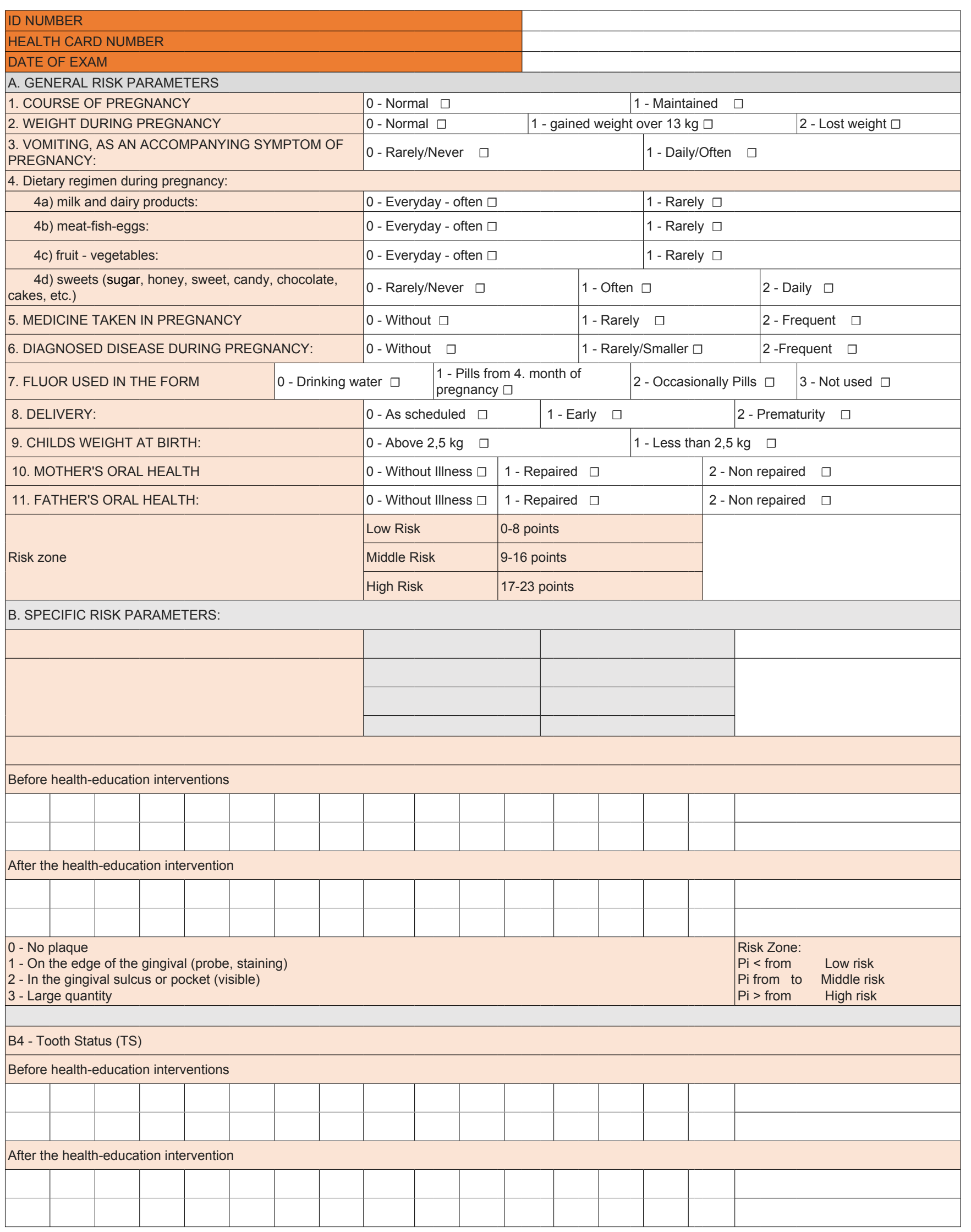


Citation: Dinarević SM, Topić B, Jurišić S, Prohić S, Sporišević L, et al. (2018) The Challenges of Detecting Risk Factors for the Development of Atherosclerosis. J Cardiovasc Dis Diagn 6: 342. doi: 10.4172/2329-9517.1000342

Page 7 of 9

\begin{tabular}{|l|l|}
\hline$H$ - healthy tooth is present & Risk zone \\
C - Caries & TS < from Low risk \\
R - Tooth root & TS from to Middle risk \\
P - Plum & TS > from $\begin{array}{c}\text { High risk } \\
\text { CT }- \text { Cured tooth }\end{array}$ \\
\hline E - Tooth removed & \\
\hline
\end{tabular}

Figure 2: Questionaries' of dental status in mothers.

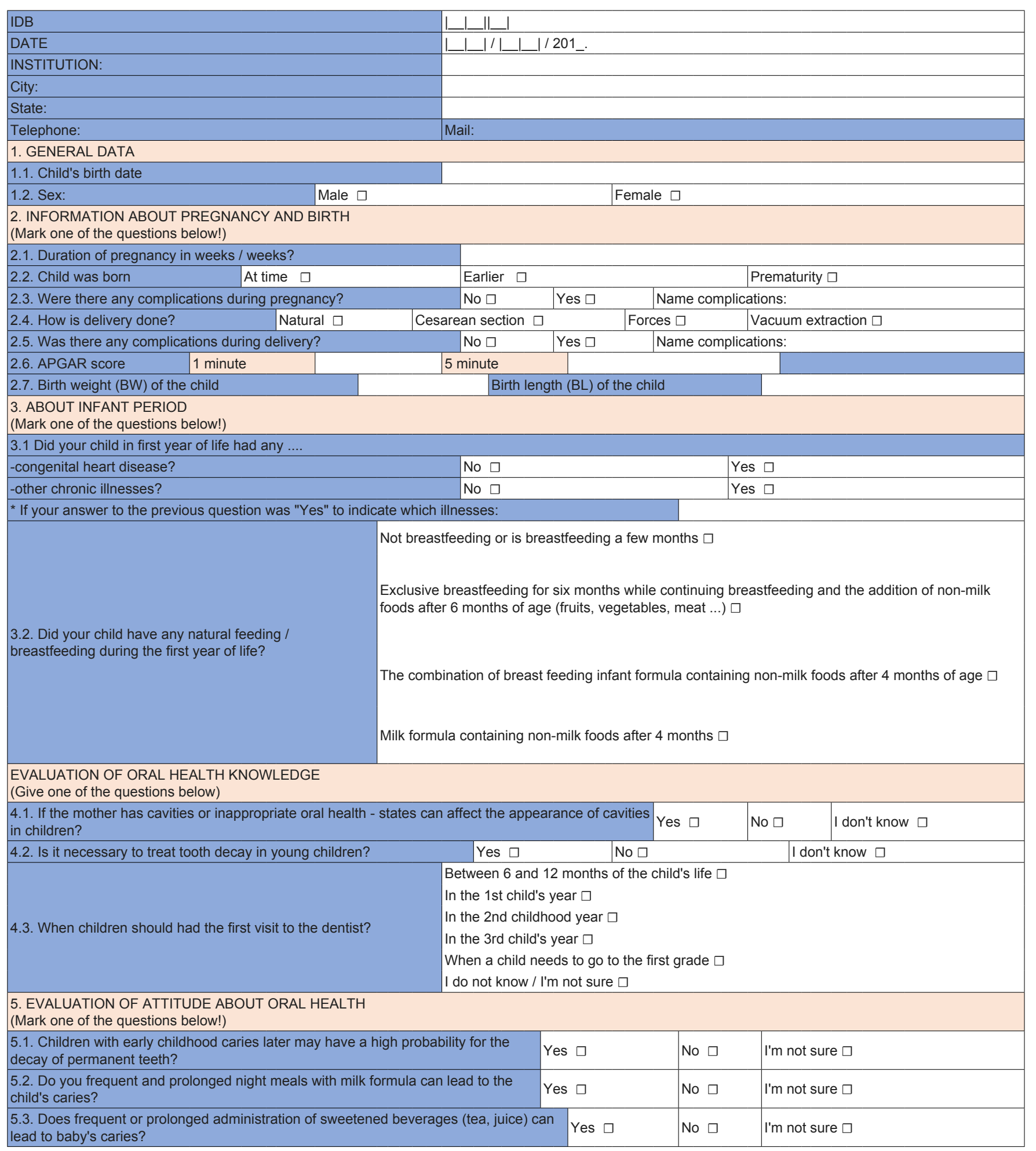


Citation: Dinarević SM, Topić B, Jurišić S, Prohić S, Sporišević L, et al. (2018) The Challenges of Detecting Risk Factors for the Development of Atherosclerosis. J Cardiovasc Dis Diagn 6: 342. doi: 10.4172/2329-9517.1000342

Page 8 of 9

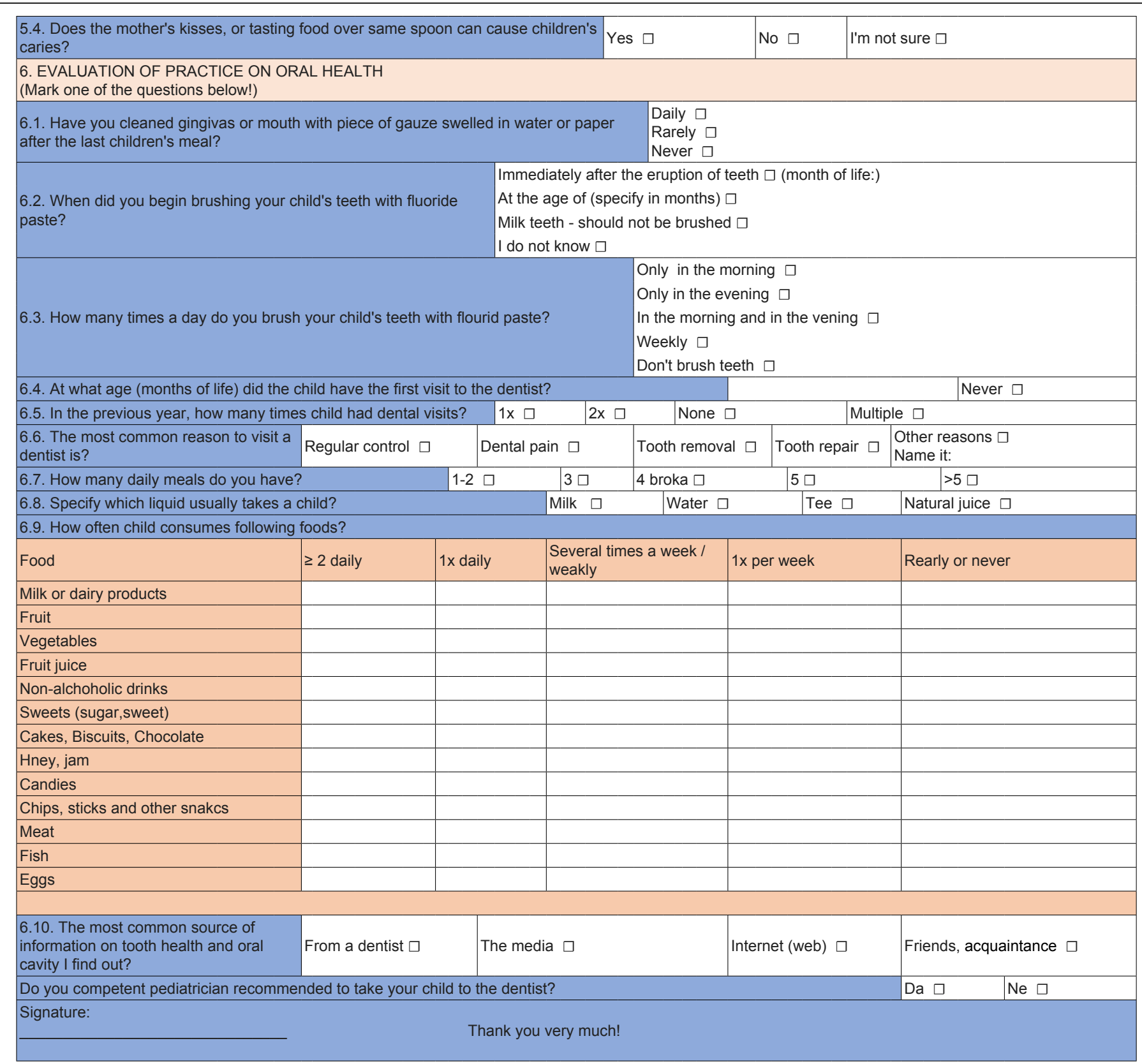

Figure 3: Childs questionnaire: The impact of oral health of pregnant women on the cardiovascular health of children.

Only 9.3\% of women in pregnancy had rare/lighter illnesses and $4.65 \%$ of respondents had bigger complications. Educational status: High school finished 8 (18.60\%) mothers, senior high school: $4(9.30 \%)$, university education: 31 (72.10\%) pregnant women.

Eating habits: $49 \%$ dairy products: daily; fruit $65 \%$ : two or more times per day; vegetables $23 \%$ : Two or more times per day; meat $51 \%$ : daily; with $14 \%$ more that eats meat several times per week; fish in $46 \%$ : once a week; in $26 \%$ rarely or never.

KEP (Cavities/Tooth extraction/seal) index: $12.32 \pm 5.7$; plaque index 0.312 ; repaired teeth $65.62 \%$; non-repaired teeth $12.5 \%$ (Tables $1-3$ ).

\section{Expected results and their significance}

The results of this research will show that a certain number of mothers have an inappropriate oral health status due firstly to insufficient oral hygiene, not adhering to appropriate eating guidelines and insufficient visits to the dentist. Using this research, we are going to show that a certain number of mothers with a bad oral health status deliver preterm newborn's and new-born's with low birth weight. We expect that children whose mothers had a bad oral health status age 3 have a worse oral health status in comparison to children whose mothers had a good oral health status. The group of children who are preterm or born with a low birth weight, age 3/4/years, would have a greater body mass index for their age and sex, greater values of blood pressure and greater thickening of the intima-media complex in comparison to the desired values of these parameters for term new-born's and new-borns of a desirable birth weight, with possible incipient signs of cardiovascular system disease including atherosclerotic, in comparison to the control group. 
Citation: Dinarević SM, Topić B, Jurišić S, Prohić S, Sporišević L, et al. (2018) The Challenges of Detecting Risk Factors for the Development of Atherosclerosis. J Cardiovasc Dis Diagn 6: 342. doi: 10.4172/2329-9517.1000342

\section{Result}

Regular dental therapy can decrease the frequency of the appearance of caries, periodontal disease in pregnant women, the frequency of prematurity, low birth weight with all its potential complications, decrease the financial costs of neonatal intensive care management and cardiovascular repercussions on a new-born's health.

\section{Discussion and Conclusion}

The results so far indicate to the awareness of pregnant women of the importance of oral health and its influence on child development. However, it is necessary to wait until the end of the study to see definitive results, the impact of mother's oral health on the developing foetus. The presented cardiovascular-oral health data base for the Balkan region can be used as a geographic, demographic and epidemiologic source of information for the detection and identification of new potential risk factors of individuals for preterm delivery and possible atherosclerosis development. Primary prevention of atherosclerosis should begin as early as possible, during pregnancy, in childhood, by creating a healthy way of life, which will be able to prevent or at least slow the development of atherosclerosis.

\section{Conflict of Interest}

None declared.

\section{References}

1. Berenson GS, Blonde CV, Farris RP Foster TA, Frank GC et al. (1979) Cardiovascular disease risk factor variables during the first year of life. Am J Dis Child 133: 1049-1057.

2. Berenson GS, Srinivasan SR, Hunter SM, Nicklas TA, Freedman DS, et al. (1989) Risk factors in early life as predictors of adult heart disease: The Bogalusa heart study. Am J Med Sci 298: 141-151.

3. Dinarević S (1994) The pathogenesis of atherosclerosis: A review. Br J Cardiol 67: 241-246

4. Berenson GS, Srinivasan SR, Bao W, Newman WP, Tracy RE, et al. (1998) Association between multiple cardiovascular risk factors and atherosclerosis in children and young adults. N Engl J Med 338: 1650-1656.

5. Dinarević SM (2017) Prevention of cardiovascular disease from an early age. $J$ Cardiovasc Dis Diagn 5: 2-5.
6. Friedewald VE, Kornman KS, Beck JD, Genco R, Goldfine A, et al. (2009) The American Journal of Cardiology and Journal of Periodontology editors' consensus: Periodontitis and atherosclerotic cardiovascular disease. J Peridontol 80: 1021-1032.

7. Teles R, Wang CY (2011) Mechanisms involved in the association between peridontal diseases and cardiovascular disease. Oral Dis 17: 450-461.

8. Boggess KA, Edelstein $\mathrm{BL}$ (2006) Oral health in women during preconception and pregnancy: Implications for birth outcomes and infant oral health. Matern Child Health 10: 169-174.

9. Hemalatha VT, Manigandan T, Sarumathi T, Aarthi Nisha V, Amudhan A (2013) Dental considerations in pregnancy: A critical review on the oral care. $J$ Clin Diagn Res 7: 948

10. Committee Opinion No. 569 (2013) Oral health care during pregnancy and through the lifespan. American College of Obstetricians and Gynecologists. Obstet Gynecol 122: 417-422.

11. Offenbacher S, Katz V, Fertik G, Collins J, Boyd D, et al. (1996) Periodontal infection as a possible risk factor for preterm low birth weight. J Periodontal 67 1103-1113.

12. Moore S, Ide M, Coward PY, Randhawa M, Borkowska E, et al. (2004) A prospective study to investigate the relationship between periodontal disease and adverse pregnancy outcome. Br Dent J 197: 251-258.

13. Jeffcoat MK, Geurs NC, Reddy MS, Cliver SP, Goldenberg RL, et al. (2001) Periodontal infection and preterm birth: Results of a prospective study. J Am Dent Assoc 132: 875-880.

14. Silk H, Douglass AB, Douglass JM, Silk L (2008) Oral health during pregnancy. Am Physician 77: 1139-1144

15. Škrinjarić I (2014) Prevention of oral diseases in children: U: Bralić I. et al. Prevention of pediatric disease, Medical publication, Zagreb pp: 412-431.

16. D. Mardešić, Benjak V Nedonošče (2016) Pediatrics: Schoolbook; In: Mardešić D (ed.) Zagreb pp: 389-397.

17. Crispi F, Bijnens B, Figueras F, Bartrons J, Eixarch E, et al. (2010) Fetal growth restriction results in remodeled and less efficient hearts in children. Circulation 121: $2427-2436$

18. Barker D (2008) Human growth and cardiovascular disease. In the window of opportunity: Pre-pregnancy to 24 months of age. Nestle Nutr Work-shop Ser Pediatr program 61: 21-38

19. Boggess KA, Urlaub DM, Moos MK, Polinkovsky M, El-Khorazaty J, et al (2011) Knowledge and beliefs regarding oral health among pregnant women. J Am Dent Assoc 142: 1275-1282. 